\title{
Supporting Material \\ Is Arg418 the Catalytic Base Required for the \\ Hydrolysis Step of the IMP Dehydrogenase Reaction?
}

\author{
Yollete V. Guillén Schlippe and Lizbeth Hedstrom* \\ Brandeis University, Waltham MA
}

Figure S1. The dependence of $\mathrm{V} / \mathrm{K}_{\mathrm{m}}\left(\mathrm{NAD}^{+}\right)$on $\mathbf{p H}$ and $\mathrm{pD}$. Conditions as described in Materials and Methods. Solid circles denote the reaction in $\mathrm{H}_{2} \mathrm{O}$, open circles denote the reaction in $\mathrm{D}_{2} \mathrm{O}$. The bell shaped $\mathrm{pH}$ dependence is well described by a model involving two ionizable groups with $\mathrm{pK}_{1}$ at 6.0 \pm 0.1 and $\mathrm{pK}_{2}=8.3 \pm 0.1$ (note that the value of $\mathrm{pK}_{1}$ must be considered under-determined because the lowest value of $\mathrm{pH}$ measured is 6.0). Since $\mathrm{V} / \mathrm{K}_{\mathrm{m}}$ includes all steps up to and including NADH release, these $\mathrm{pK}_{\mathrm{a}}$ values derive from ionizations of $\mathrm{E} \cdot \mathrm{IMP}$ and/or $\mathrm{NAD}^{+}$required for $\mathrm{NAD}^{+}$binding, hydride transfer, and NADH release. The origin of $\mathrm{pK}_{1}$ is unclear. One possibility is the ionization of the phosphate of enzyme-bound IMP ( $\mathrm{pK}_{\mathrm{a}}=5.8$ in solution). However, in human IMPDH, no ionizations are observed in IMP binding or the reaction of 2-Cl-IMP $(1,2)$, which is inconsistent with this hypothesis. Other possible candidates include Asp261 and/or Asp338; these two residues are involved in $\mathrm{NAD}^{+}$binding and hydride transfer $(3,4)$. Likely candidates for the ionization responsible for $\mathrm{pK}_{2}$ include the hypoxanthine ring of IMP $\left(\mathrm{pK}_{\mathrm{a}}=8.9\right.$ in solution) and Cys $319\left(\mathrm{pK}_{\mathrm{a}}=8.4\right.$ in E. coli IMPDH (5)). Similar ionizations are observed in the dependence of $\mathrm{V} / \mathrm{K}_{\mathrm{m}}\left(\mathrm{NAD}^{+}\right)$on $\mathrm{pD}: \mathrm{pK} \mathrm{K}_{1}=5.9 \pm 0.1$ and $\mathrm{pK}_{2}=8.0 \pm 0.1$. An inverse $\mathrm{SIE}=0.70 \pm 0.1$ is observed in the $\mathrm{pH}$-independent value of $\mathrm{V} / \mathrm{K}_{\mathrm{m}}\left(\mathrm{NAD}^{+}\right)$. The most likely origin of this inverse SIE is an equilibrium isotope effect for proton transfer involving Cys319.

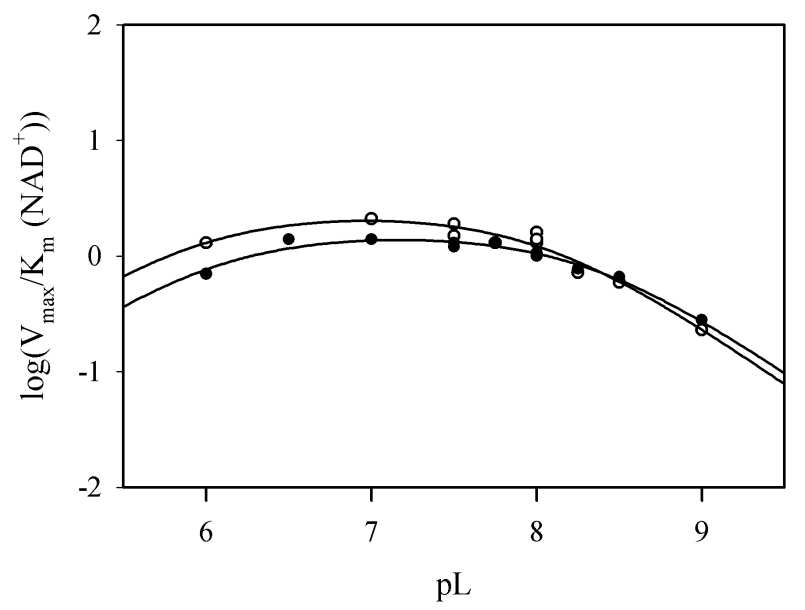


Figure S2. The pre-steady state reaction of the Thr321Ala variant. The reaction was monitored by absorbance (black) and fluorescence (red). Enzyme was mixed with both substrates. Final concentrations: $2.4 \mu \mathrm{M}$ enzyme, $100 \mu \mathrm{M}$ IMP and 5 mM NAD ${ }^{+}$.

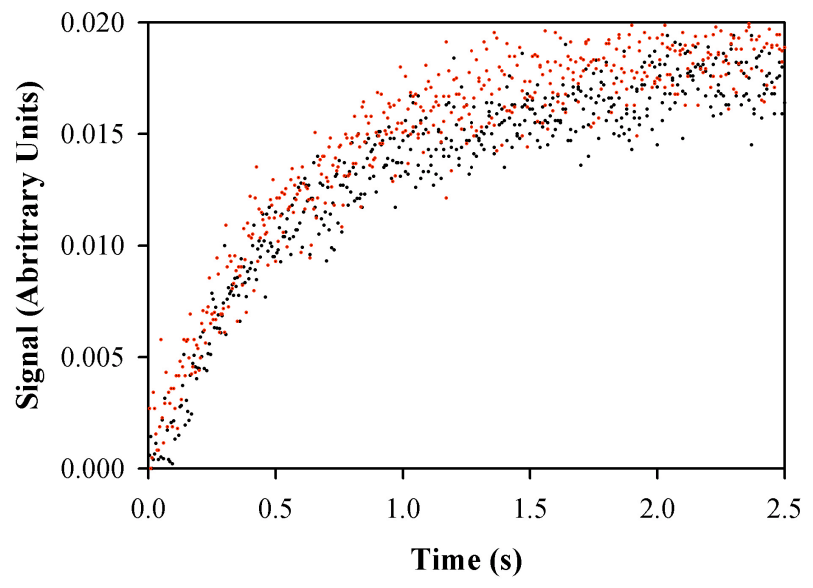

Figure S3. The activity of the Arg418Lys variant. The dependence of the initial velocity on the concentration of $\mathrm{NAD}^{+}$at saturating IMP concentrations. Data were fit to equation $v=\mathrm{V}_{\mathrm{m}} /(1+$ $\left.\mathrm{K}_{\mathrm{a}} /\left[\mathrm{NAD}^{+}\right]+\left[\mathrm{NAD}^{+}\right] / \mathrm{K}_{\mathrm{ii}}\right)$.

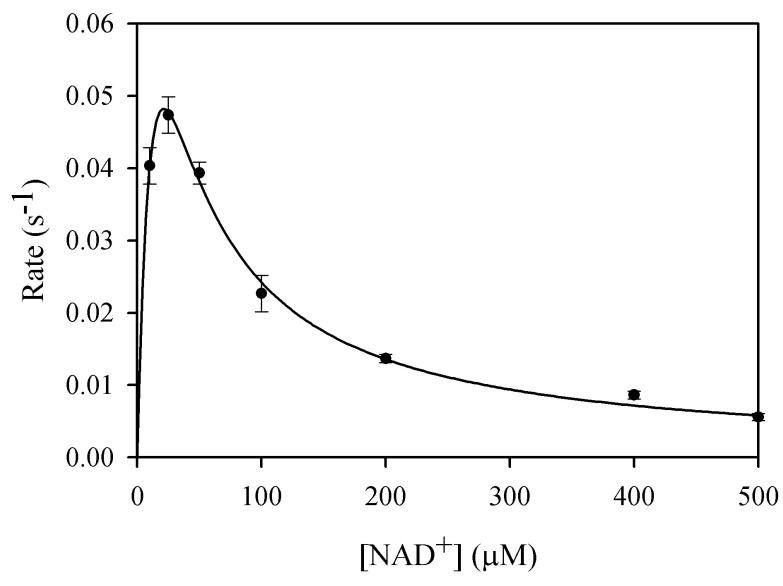


Table S1. Pre-Steady-State Kinetic Characterization of Wild-Type and Mutant IMPDHs. Pre-steady state progress curves were measured for the reaction of E•IMP with $\mathrm{NAD}^{+}$and fit to equation 4 or 5 as appropriate. Due to strong $\mathrm{NADH}$ and $\mathrm{NAD}^{+}$inhibition, the pre-steady-state progress curves for Arg418Lys did not fit these equations. This reaction was simulated using Dynafit (6).

\begin{tabular}{lllllll}
\hline enzyme & $\mathrm{k}_{\text {burst1 }}\left(\mathrm{s}^{-1}\right)$ & Amp $_{1}$ & $\mathrm{k}_{\text {burst2 }}\left(\mathrm{s}^{-1}\right)$ & $\mathrm{Amp}_{2}$ & $\mathrm{k}_{\text {fluor1 }}\left(\mathrm{s}^{-1}\right)$ & $\mathrm{k}_{\text {fluor2 }}\left(\mathrm{s}^{-1}\right)$ \\
\hline wild-type $^{a}$ & 62 & 0.45 & n.a. & n.a. & n.a. & 6.5 \\
Thr321Ala $^{c}$ & 1.4 & $\geq 0.55$ & n.a. & n.a. & 1.7 & n.a. \\
Arg418Ala $^{b}$ & 110 & 0.68 & 3.7 & 0.35 & n.a. & 6.2 \\
$\operatorname{Arg}^{2} 418 \mathrm{Gln}^{c}$ & $\geq 48$ & $\geq 0.42$ & $\geq 2.3$ & $\geq 0.21$ & $\geq 46$ & $\geq 3.6$
\end{tabular}

${ }^{a}$ These values are from ref. (7). ${ }^{b}$ These values are from ref. (8). ${ }^{c} k_{o b s}$ at $10 \mathrm{mM} \mathrm{NAD}^{+} .{ }^{d} k_{o b s}$ at $2 \mathrm{mM} \mathrm{NAD}{ }^{+}$. n.d., not determined. n.a., not applicable.

Scheme S3. The pH dependence of $\underline{K}_{\underline{c}^{*}}$

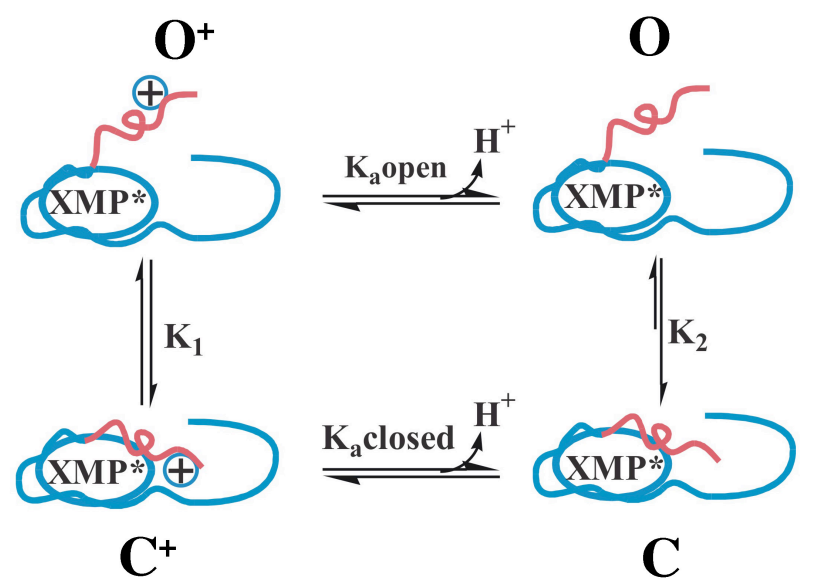

Derivation of Equation 10.

$$
\begin{aligned}
& \mathrm{K}_{\mathrm{c}}=\left(\left[\mathrm{C}^{+}\right]+[\mathrm{C}]\right) /\left(\left[\mathrm{O}^{+}\right]+[\mathrm{O}]\right) \\
& \mathrm{K}_{1}=\left[\mathrm{O}^{+}\right] /\left[\mathrm{C}^{+}\right] \\
& \mathrm{K}_{2}=[\mathrm{O}] /[\mathrm{C}] \\
& \mathrm{K}_{\mathrm{a} \text { closed }}=[\mathrm{C}]\left[\mathrm{H}^{+}\right] /\left[\mathrm{C}^{+}\right] \\
& K_{c}=\mathrm{K}_{1} \mathrm{~K}_{2}\left(\mathrm{~K}_{\text {a closed }}+\left[\mathrm{H}^{+}\right]\right) /\left(\mathrm{K}_{1} \mathrm{~K}_{\mathrm{ac}}+\mathrm{K}_{2}\left[\mathrm{H}^{+}\right.\right.
\end{aligned}
$$




\section{References.}

1. Bruzzese, F. J., and Connelly, P. R. (1997) Allosteric properties of inosine monophosphate dehydrogenase revealed through the thermodynamics of binding of inosine 5'-monphosphate and mycophenolic acid. Temperature dependent heat capacity of binding as a signature of ligand coupled conformational equilibria, Biochemistry 36, 10428-10438.

2. Markham, G. D., Bock, C. L., and Schalk-Hihi, C. (1999) Acid-base catalysis in the chemical mechanism of inosine monophosphate dehydrogenase., Biochemistry 38, 4433-4440.

3. Kerr, K. M., and Hedstrom, L. (1997) The roles of conserved carboxylate residues in IMP dehydrogenase and identification of a transition state analog, Biochemistry 36, 13365-13373.

4. Gan, L., Petsko, G. A., and Hedstrom, L. (2002) Crystal structure of a ternary complex of Tritrichomonas foetus inosine 5'-monophosphate dehydrogenase: NAD orients the active site loop for catalysis, Biochemistry 41, 13309-1317.

5. Gilbert, H., and Drabble, W. (1980) Active-site modification of native and mutant forms of inosine 5'-monophosphate dehydrogenase from Escherichia coli K12., Biochem. J. 191, 533-541.

6. Kuzmic, P. (1996) Program DYNAFIT for the analysis of enzyme kinetic data: application to HIV proteinase, Anal. Biochem. 237, 260-73.

7. Digits, J. A., and Hedstrom, L. (1999) Kinetic mechanism of Tritrichomonas foetus inosine-5'monophosphate dehydrogenase, Biochemistry 38, 2295-2306.

8. Guillén Schlippe, Y. V., Riera, T. V., Seyedsayamdost, M. R., and Hedstrom, L. (2004) Substitution of the Conserved Arg-Tyr Dyad Selectively Disrupts the Hydrolysis Phase of the IMP Dehydrogenase Reaction, Biochemistry 43, 4511-21. 